simple circumstance of the sarcolemma being distinct from the common sheath it has been supposed that its nature differs likewise; but this inference has been drawn, too hastily, from an observation made on the more central portion of the fibre. If we examine the common sheath of the muscle itself we find it generally distinct from the surrounding cellular tissue, and presenting a clean, polished surface, -in no sensible respect differing from the sarcolemma, with the exception of its greater density. We may thas regard the common sheath as a portion of the general cellular tissue, isolated from the rest, excepting at its extremities, and sending down processes from its inner surface between the fasciculi; and we may regard the sarcolemma as a portion similarly isolated from the general sheath. Whether it give sinilar processes to surround the individual fibrillæ remains to be considered.

The elements of cellular tissue may be said to be two, viz., the ordinary filamentous structure derived from the original cells and cytoblastema, and the yellow fibre, \&c., formed by the elongation and interunion of the nuclei. The first are rendered indistinct by acetic acid, which thus affords a more ready view of the nuclear portion, Now, in the sarcolemma, we must bear in mind its extreme tenuity, caused by the matter of a few cells being spread out over a large surfare. Hence, also, the fewness of the nuclei that are found in it. In spealking of the nuclei of this membrane $I$ refer to the muscular corpuscles of Mr. Bowman, and I should, therefore, state my reasons for altering their designation. I believe them to be identical in their nature with the nuclei of ordinary cellular tissue, from the evident ratio that they bear to the tenuity of the membrane, and consequently the smail quantity of cell-mattei required in its formation, and from their behaviour under chemical reaction. I would also refer them to the fibre sheath rather than to the proper sarcous material, because of the regularity of their disposition on the surface of fibre. But other similar corpuscles are observed disseminated in the mass, which at first sight do not present this regular disposition.What does this go to prove? That these bodies belong to the proper substance of the muscle? No. This appearance would rather suggest to us the existence of sarcolemmatous processes corresponding with those that are sent down from the general sheath, between the larger fasciculi; and, by carefully varying the focus of the microscope, I think I can perceive an arrangement which would support my view.

but to proceed with our original question. We are well acquainted with the continuity and identity of the fibrous and cellular tissues, they differing chiefly in this, namely, that in the former the vuclear filamentous portion is the more developed. Now, let us

No. 1054. consider the filaments of the tendon as being continuous with the sheaths, or, rather, closed sacs of the muscle and its primitive fasciculi. In those of the latter (the sarcolemmata) we find the nuclei free and ununited from their remoteness; and we can trace (at the extremities of the organ) the gradual condensation of the tissue, and the consequent approximation of its fibres, where they unite, after the ordinary mode of cellular structure, until we arrive at the tendon itself. The transition, although rapid, is so gradual that it is impossible to fix the limits of any one region of condensation.

With this view of the constitution of tendon it is easy to see in what manner it is influenced by the contraction of its muscle. And I may add, that it is supported by an observation of $M$. Lauth, showing the laxness of the sarcolemma when the muscle is in a state of contraction. I have the honour, $\mathrm{Sir}$, to remain your most obedient servant,

Dorset street, Portman square, Nov, 1, 1843.

\section{MEDICAL INTERFERENCE IN PROTRACTED LABOURS.}

To the Editor,-Sir: In THE LANCET for Sept. 30, 1843 (page 941), a case of laceration of the perineum during labour is related by Mr. Robinson, of Lewes. The case is not rendered sufficiently complete to enable a true estimate of its real nature to be formed. We are not informed of the patient's age, nor of the state of her health previously to the commencement of labour, nor at what period the membranes broke; neither are we told when thelabour terminated. It is stated that on examination the parts appeared to be unusually small, and the perineum peculiarly rigid and unyielding; and that previously to marriage an abscess had formed in the parts, the cicatrix occasioned by the opening of that abscess being considered to be the cause of the obstruction or rigidity of the perineum. Hot fomentations, with a view to relax the rigidity of the parts, seem to have been the only means used.

Independently of the severe and pro. tracted sulfering which this woman under. went before the birth of her child, it appears that her condition afterwards was serious and her recovery tedious, even under judi. cious treatment. A case similar to this one is reported in TuE LanceT for February 4, 1813 , on which case I made some observations in a subsequent number of The LANCEr, and as those observations had for their object the safe and speedy relief of such cases, I beg to refer MIr. Kobinson to them, with very little doubt that he would, by careful trial of the means advised, save himself much time and anxiety, and his pa. tient much suffering. 
It is truly pitiable to see works still issuing from the press professing to guide the obstetrician, advising as little interference as possible with nature in the usual forms of protract,od and tedious labours. Their authors seem never to consider that, although nature, in her normal condition, undeviatingly performs her operations well, yet th tt in her abnormal or morbid states she $i$; uniformly defective in accomplishing her natural processes, the degree of this deficiency being always proportioned to the extent of the disturbing causes.

The accoucheur should immediately ascertain the nature of the obstructing causes, and the means suited for their removal, and then, without waiting until nature is exhausted by her exertions to overcome resistances that are beyond her powers, he will instantly resort to those means which are calculated to subdue the abnormal opposition, as when the operations of nature are thus unopposed delivery will be speedily effected. So far as I have observed, these obstructing causes to delivery may, by careful observation, generally be easily recognised, and the remedial means as readily known and applied. The advocates for non-interference might as well argue that as, in many complaints, patients recover without medical treatment, nature should always be left to her own resources so long as no immediate danger appears. Yet in this way many lives must be lost which might be saved, and many recoveries grievously protracted. The same reasoning applies to parturient women in protracted labours, where, without removing the causes of delay, they must, for a great number of hours, suffer unnecessarily, and recover tediously if surviving; but not unfrequently both mother and child are lost. In my opinion such views and recommenda. tions are most injurious, for when explained to the sufferers by their medical attendant, as the mode of practice pursued by men of great experience, the patient submits, and the practitioner considers that he is doing " all that duty demands of him." Yet were general practitioners oftener left to draw from the resources of their own minds they would (in many instances at least) conduct their cases more in conformity with the requirements of nature. I am, Sir, your obedient servant,

$$
\text { Paisley, Oct. 31, } 1843 .
$$

John Craig.

Sterility.-If the mule be unproductive it is (in the female) that the animal is not liable to periods of heat, as are all other female quadrupeds, consequent on the ovaries being destitute of Graafian follicles. The male of the same kind is equally incapable of propagation, because the semen is destitute of spermatic animalcules, "which, apparently, constitute the fecundating principle in all animals."-Raciborski.

\section{THE IAANCET.}

London, Saturday, November 11, 1843.

The virtues of simple arithmetic-which, when occupied in the deduction of medical facts, is, by general consent, called numbering-have no operation more important than that of calculating the efficacy of remedies, for numbering is the only method by which their qualities can be satisfactorily proved, though almost wholly neglected by us, very many medicines which are in daily use being indebted for their character simply to hearsay, and not to that of effectual test. Accordingly, the most diverse opinions prevail, even among intelligent practitioners, with regard to the pretensions of numerous presumed therapeutic agents. One, for example, says that he has the greatest confidence in the alterative virtues of sarsaparilla; another, with equal opportunities of observation, declares his belief that its qualities are precisely equivalent to those of chopped hay. Some experimenters will affirm that iodide of potassium, given in doses of more than eight or ten grains, will act as an irritant, producing diarrhoea, vomiting, and other disagreeable effects ; while certain inquirers, on the other hand, assert that six drachms of that substance may be given daily, in divided doses, for many weeks, and even balf an ounce of it at a single dose, without inconvenience to the patient.

It is quite clear that - the constitution and condition of the patients being analogousone or other of these statements is egregiously erroneous, although both profess to be founded on personal observation. It is needless to multiply instances. There are, in daily use, a great number of alleged medicinal substances, with reference to which it is disputed whether they have any operation at all, or, admitting that they have some, what that operation is, and under what circumstances it occurs. But to ascertain whether a given substance be active or inert, in relation to the animal economy, and, 